\title{
Mechanical properties of hot pressed CoCrMo alloy compacts for biomedical applications
}

\author{
B. Henriques ${ }^{\mathrm{a}, \mathrm{b}, *}$, A. Bagheri ${ }^{\mathrm{a}}$, M. Gasik ${ }^{\mathrm{c}}$, J.C.M. Souza ${ }^{\mathrm{a}, \mathrm{d}}$, O. Carvalho ${ }^{\mathrm{a}}$, F.S. Silva ${ }^{\mathrm{a}}$, R.M. Nascimento ${ }^{\mathrm{e}}$ \\ ${ }^{a}$ CMEMS-UMinho, University of Minho, Campus de Azurém, 4800-058 Guimarães, Portugal \\ ${ }^{\mathrm{b}}$ Federal University of Santa Catarina, Campus Blumenau, 89065-300 Blumenau, SC, Brazil \\ ${ }^{\mathrm{C}}$ Department of Materials Science and Engineering, School of Chemical Technology, Aalto University Foundation, 00076 Aalto, Espoo, Finland \\ d School of Dentistry (ODT), Post-Graduation Program in Dentistry (PPGO), Federal University of Santa Catarina (UFSC), Campus Trindade, 88040-900 Florianópolis, SC, Brazil \\ ${ }^{\mathrm{e}}$ Department of Materials Sciences, Federal University of Rio Grande do Norte (UFRN), 59072-970 Natal, RN, Brazil
}

\section{A R T I C L E I N F O}

\section{Article history:}

Received 19 April 2015

Revised 28 May 2015

Accepted 7 June 2015

Available online 20 June 2015

\section{Keywords:}

CoCrMo alloy

Hot pressing

Mechanical properties

Biomedical applications

\begin{abstract}
A B S T R A C T
This study aimed at investigating the influence of the processing conditions on the mechanical properties of hot pressed compacts of a CoCrMo biomedical alloy.

Several hot pressed CoCrMo compacts were processed in vacuum $\left(10^{-2} \mathrm{mbar}\right)$, at a pressure of $60 \mathrm{MPa}$ with different temperatures $\left(900^{\circ} \mathrm{C}, 1000^{\circ} \mathrm{C}\right.$ and $\left.1100{ }^{\circ} \mathrm{C}\right)$ and different times $(10 \mathrm{~min}, 30 \mathrm{~min}$ and $60 \mathrm{~min}$ ). Compacts were examined by SEM/EDS. The transverse rupture strength, Young's Moduli and hardness were determined. The fracture surface of compacts were also examined.

The compacts hot pressed at $900{ }^{\circ} \mathrm{C}$ exhibited lower TRS than those processed at $1000^{\circ} \mathrm{C}$ and $1100{ }^{\circ} \mathrm{C}$, which showed similar strength values, regardless the sintering time. The $900{ }^{\circ} \mathrm{C}$ compacts showed also lower YM and higher porosity. Lower hardness values were registered for $900^{\circ} \mathrm{C}$ compacts while $1000{ }^{\circ} \mathrm{C}$ compacts exhibited the highest values. The fracture surface analyses revealed fragile fracture for $900{ }^{\circ} \mathrm{C}$ compacts $(10 \mathrm{~min}$ and $30 \mathrm{~min})$ and $1000^{\circ} \mathrm{C}(10 \mathrm{~min})$. The remaining compacts exhibited ductile fracture.

A full characterization of the mechanical properties of hot pressed CoCrMo compacts has been made and the selection of the processing parameters according to the desired mechanical properties is now possible.
\end{abstract}

(C) 2015 Elsevier Ltd. All rights reserved.

\section{Introduction}

Co-Cr-Mo alloys are one of the most important biomaterials used in the production of implants and dental prosthetic infrastructures due to its high stiffness, strength, wear and corrosion resistance [1-7]. The tarnish and corrosion resistance of these alloys are provided by the presence of chromium in the alloy, which should not greatly exceed $30 \%$ for ease of casting. Molybdenum contributes to the strength of the alloy [8]. The structures made of these alloys are mainly obtained by casting. However, they should undergo thermal treatment to overcome the drawbacks of the undesired formation of $\mathrm{M}_{7} \mathrm{C}_{3}$ carbides $(\mathrm{M}=\mathrm{Co}, \mathrm{Cr}$ or $\mathrm{Mo})$ and $\sigma$-sigma brittle phase at the inderdentritic regions $[9,10]$. These elements reduce the strength and ductility of the alloy. Porosity defects are also associated with cast $\mathrm{Co}-\mathrm{Cr}-\mathrm{Mo}$

\footnotetext{
* Corresponding author at: CMEMS-UMinho, University of Minho, Campus de Azurém, 4800-058 Guimarães, Portugal.

E-mail address: brunohenriques@dem.uminho.pt (B. Henriques).
}

parts. A tight control of the thermal treatment parameters should exist since the grain growth negatively impacts the strength and fatigue properties of the alloy. In order to overcome the limitations in terms of mechanical properties of the cast CoCrMo alloys, wrought parts have been used due to its finer and more homogeneous microstructure. The Powder Metallurgy (PM) route is also an option when the fine grain microstructures and high mechanical properties are requested. Additionally, more attention should be paid to this route as it is highly related to the Powder Metallurgy (PM) based Computer Aided Design/Computer Aided Manufacturing (CAD/CAM) systems that allow the production of customized parts $[11,12]$. These systems offer further advantages such as short production times and the ability of processing materials with special properties like gradient porous materials [13] or composite materials [14-21].

The properties of the compacts are highly influenced by the PM route that is used in their production [1]. Hence, components obtained by press and sinter technique often exhibit porosity, which negatively affects its mechanical and electrochemical 
behavior $[22,23]$. On the other hand, routes that include hot consolidation of powders such as hot pressing (HP) and hot isostatic pressing (HIP) address these problems by the simultaneous application of temperature and pressure to the compact [6,24].

Little attention has been given to the hot pressing of CoCrMo alloys and to the mechanical and electrochemical properties of compacts thus obtained. Thus, few studies can be found on this topic in literature. Chen et al. [6] and Doni et al. [5,25] performed studies on the wear properties of CoCrMo hot pressed compacts. Sato et al. [26,27] and Naoyuki et al. [28] reported some results on the mechanical properties of dense and porous CoCrMo compacts.

With this study, authors aimed to investigate the influence of the hot pressing parameters, namely time and temperature, on the mechanical properties of a CoCrMo alloy used in biomedical applications.

\section{Material and methods}

A CoCrMo dental alloy (Nobil4000, Nobilmetal, Villafranca d'Asti, Italy) was used in this study in the form of air atomized powder. The composition of alloy is presented in Table 1. The powder particles have spherical shape (Fig. 1) and the following size distribution: $D_{10}=4.44 \mu \mathrm{m} ; D_{50}=8.27 \mu \mathrm{m}$ and $D_{90}=12.76 \mu \mathrm{m}$.

Rectangular CoCrMo compacts $(40 \mathrm{~mm} \times 6 \mathrm{~mm} \times 1 \mathrm{~mm})$ were produced by hot pressing CoCrMo powders in a graphite die at three selected temperatures $\left(900^{\circ} \mathrm{C}, 1000^{\circ} \mathrm{C}\right.$ and $\left.1100^{\circ} \mathrm{C}\right)$ during three selected times $(10 \mathrm{~min}, 30 \mathrm{~min}$ and $60 \mathrm{~min})$. The graphite die was painted with zirconium oxide paint in order to impede carbon to diffuse to metal substrates. Hot pressing was performed under vacuum $\left(10^{-2} \mathrm{mbar}\right)$. All compacts were ground until mirror finishing for microscope observation. Afterwards, they were ultrasonically cleaned in an alcohol bath for $10 \mathrm{~min}$ and rinsed in distilled water for another $10 \mathrm{~min}$ to remove contaminants.

Table 1

Chemical compositions of the powders (wt.\%).

\begin{tabular}{lllll}
\hline Co & Cr & Mo & Si & Impurities \\
\hline 62 & 31 & 4 & 2.2 & Mn-Fe-W \\
\hline
\end{tabular}

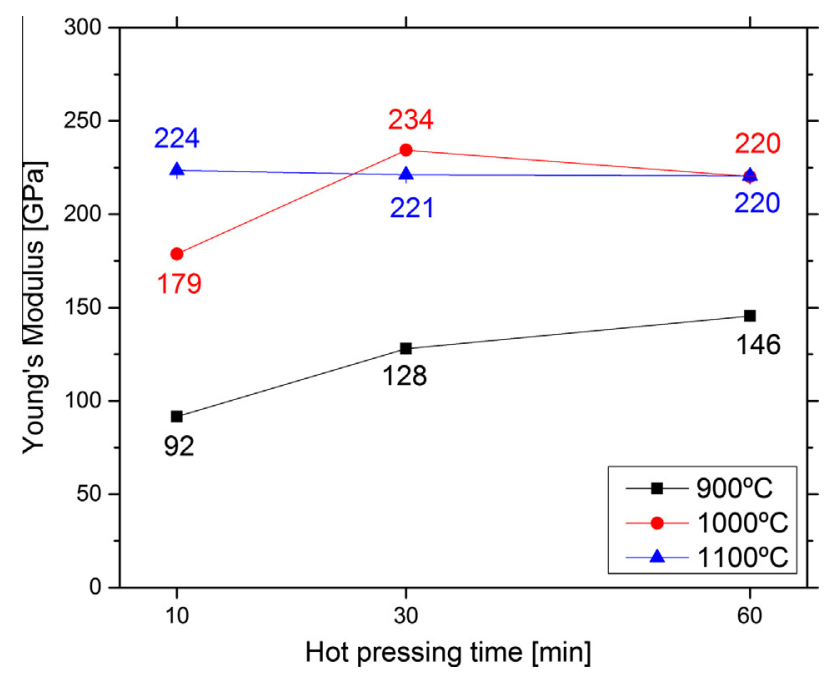

Fig. 1. Young's Moduli of the CoCrMo compacts hot pressed at different conditions of temperature and time.
Microhardness evaluation (Microhardness tester, type $M$, Shimadzu, Japan) was performed along the length of the compacts. The mean value and standard deviation was then calculated.

The transverse rupture strength (TRS) of the HP samples was obtained by the means of three-point flexural tests. Transverse rupture strength (TRS) was calculated as follows:

$\sigma_{T R S}=\frac{3 F L}{2 b h^{2}}$

where $\sigma_{T R S}$ is the transverse rupture strength of the compacts (MPa), $F$ is the force required to rupture the compacts $(\mathrm{N}), L$ is the length of compacts span relative to fixture $(35 \mathrm{~mm}), b$ is the width of the compacts (mm) and $h$ is the thickness of compacts ( $\mathrm{mm}$ ).

After flexural tests the fracture surface of the compacts were examined by the means of scanning electron microscopy - SEM (JSM-6390LV, JEOL, Tokyo, Japan). Before SEM examination, fracture surfaces were coated, by sputtering, with a layer of $10 \mathrm{~nm}$ of 80Au20Pd.

\section{Results}

Fig. 1 shows the Young's Moduli (YM) of the hot pressed compacts. The $900{ }^{\circ} \mathrm{C}$ compacts exhibited lower YM than the $1000^{\circ} \mathrm{C}$ and $1100^{\circ} \mathrm{C}$ compacts. They showed increasing YM with increasing hot pressing stages. All the $1000^{\circ} \mathrm{C}$ and $1100^{\circ} \mathrm{C}$ compacts exhibited the same $\mathrm{YM}$, except the $1000^{\circ} \mathrm{C}$ sintered during $10 \mathrm{~min}$.

The results of the transverse rupture strength (TRS) tests are presented in Fig. 2. The $900{ }^{\circ} \mathrm{C}$ compacts exhibited low strength values when compared to other compacts, with the latter showing similar results. Longer hot pressing times showed to have a great impact on the strength of the $900{ }^{\circ} \mathrm{C}$ compacts. On the other hand, the strength of $1000^{\circ} \mathrm{C}$ and $1100{ }^{\circ} \mathrm{C}$ compacts did not show to be significantly influenced by longer hot pressing stages. Hence, after a 10 min stage, the compacts hot pressed at $1000^{\circ} \mathrm{C}$ and $1100{ }^{\circ} \mathrm{C}$ have achieved their maximum strength and longer sintering times did not result in further strengthening. The $1000^{\circ} \mathrm{C}$ compacts exhibited slightly higher strength than the $1100{ }^{\circ} \mathrm{C}$ compacts.

The analysis of porosity is plotted in Fig. 3. The hot pressing time showed to have a positive impact on the reduction of porosity in the three temperatures tested. The highest porosity registered was observed in the $900{ }^{\circ} \mathrm{C}$ compacts hot pressed during $10 \mathrm{~min}$. All compacts hot pressed during $60 \mathrm{~min}$ were considered fully dense with some of them exhibiting a residual level of porosity.

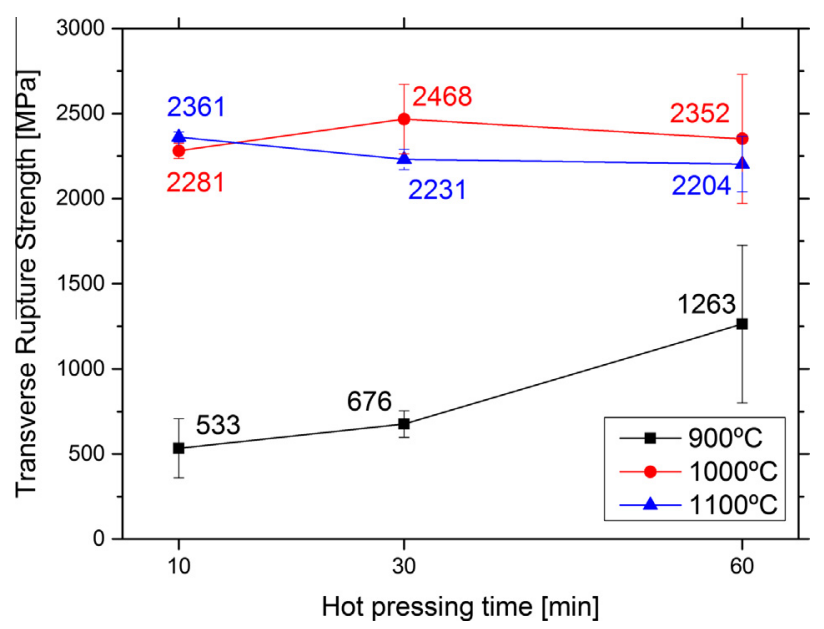

Fig. 2. Transverse rupture strength (TRS) of the CoCrMo compacts hot pressed at different conditions of temperature and time. 


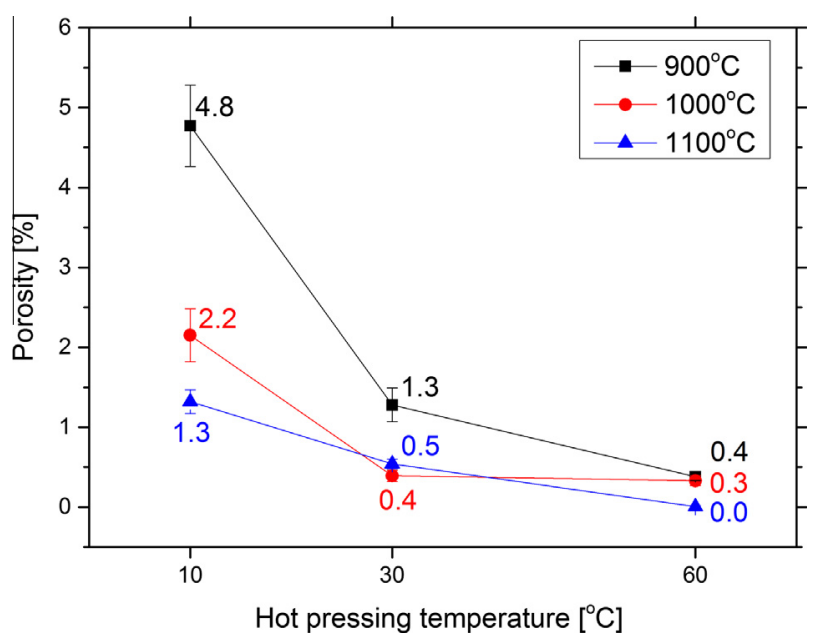

Fig. 3. Porosity of the CoCrMo compacts hot pressed at different conditions of temperature and time.

The hardness values are plotted in Fig. 4 . The $900{ }^{\circ} \mathrm{C}$ compacts exhibited the lowest values and their hardness increased sharply with the increase of hot pressing time. The $1000^{\circ} \mathrm{C}$ and $1100^{\circ} \mathrm{C}$ compacts exhibited higher hardness values with the former compacts being harder than the latter. The increase of the hot pressing times resulted in a relative increase in the hardness values for these two types of compacts.

The extension to rupture of compacts was also examined and the results are presented in Fig. 5. The $900{ }^{\circ} \mathrm{C}$ compacts exhibited very low extension to rupture, regardless the hot pressing time, revealing a brittle behavior. The $1000{ }^{\circ} \mathrm{C}$ compacts showed higher values relative to the former compacts. The higher extension to rupture values were registered for the compacts hot pressed at $1100^{\circ} \mathrm{C}$, revealing a markedly ductile behavior.

In Fig. 6 the micrographs of the compacts obtained after the different hot pressing conditions are depicted, with the porosity and microstructure being visible. Fig. 7 shows the fracture surface of the compacts after the three point flexural test. It is seen that bonds between powders were very weak in the $900{ }^{\circ} \mathrm{C}$ compacts hot pressed during $10 \mathrm{~min}$ and $30 \mathrm{~min}$. Necks between particles were in a early stage and starting to form. At the same

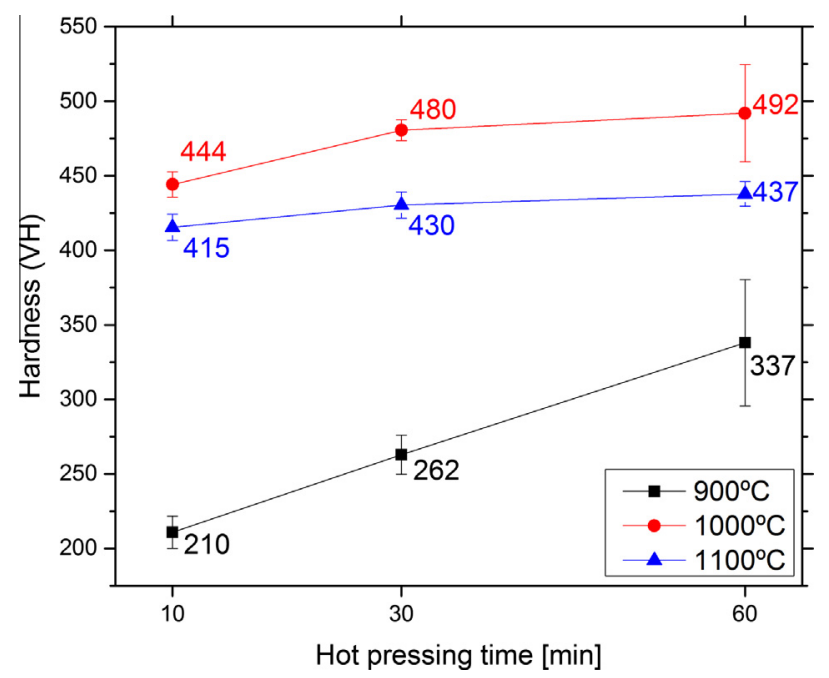

Fig. 4. Hardness vickers of the CoCrMo compacts hot pressed at different conditions of temperature and time.

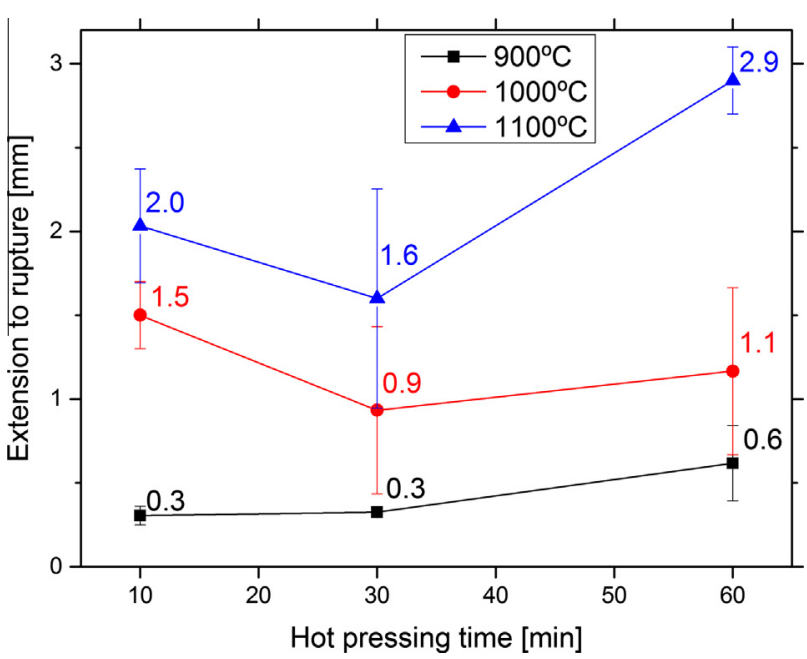

Fig. 5. Extension to rupture of the CoCrMo compacts at different conditions of temperature and time.

temperature, compacts hot pressed during 60 min revealed a significant improvement in the bonds between powders, with deformation of the particles being noticed at the fracture surface. The level of deformation of the particles verified in the $1000^{\circ} \mathrm{C}$, hot pressed for $10 \mathrm{~min}$, is similar to that exhibited by compacts hot pressed at $900{ }^{\circ} \mathrm{C}$ during $60 \mathrm{~min}$. The remaining compacts exhibited extensive deformation of the powders at the fracture surface, evidencing good bond between them and an advanced stage in the sintering process.

\section{Discussion}

Before discussing the results, some considerations on the CoCrMo alloy used in this study must be made. It is a $\mathrm{Co}-\mathrm{Cr}$ biomedical alloy that fulfills the ANSI/ADA Specifications No. 14 (ISO 6871) in terms of chromium and cobalt weight, which should be no less than $20 \%$ and $85 \%$, respectively (Table 1 ). Cobalt is the major element in the alloy and its content in the alloy is regarded for the elastic modulus, strength and hardness [10]. Chromium is the second major element in the alloy (Table 1) and is responsible for its corrosion resistance. Its content in the alloy should not exceed significantly $30 \%$ because it turns casting more difficult and due to the formation of a brittle ( $\sigma$-sigma) phase $[10,26-$ $28]$. The chemical composition and microstructure of the hot pressed CoCrMo compacts using this alloy can be found in another study performed by the same authors [16]. The same study showed that hot pressed compacts revealed greater corrosion resistance than cast compacts.

The temperatures range used in this work $\left(900-1100{ }^{\circ} \mathrm{C}\right)$ was in line with temperatures used in other studies on hot pressed $\mathrm{Co}-\mathrm{Cr}$ alloys $[24,26,27]$. The temperature of $900{ }^{\circ} \mathrm{C}$ has produced the compacts with the lowest mechanical properties, especially when the hot pressing time of $10 \mathrm{~min}$ and $30 \mathrm{~min}$ were used. The compacts thus produced showed high porosity, low stiffness, low strength, low hardness and exhibited very fragile behavior. When the hot pressing time was extended to $60 \mathrm{~min}$, a great reduction in porosity was observed followed by a significant improvement of the mechanical properties. Nevertheless, the properties exhibited by the compacts sintered at $900{ }^{\circ} \mathrm{C}$ during $60 \mathrm{~min}$ were roughly the same as those obtained for the compacts hot pressed at $1000{ }^{\circ} \mathrm{C}$ during $10 \mathrm{~min}$.

The properties obtained for the compacts hot pressed at $100{ }^{\circ} \mathrm{C}$ and $1100{ }^{\circ} \mathrm{C}$ did not show significant differences, except for the 

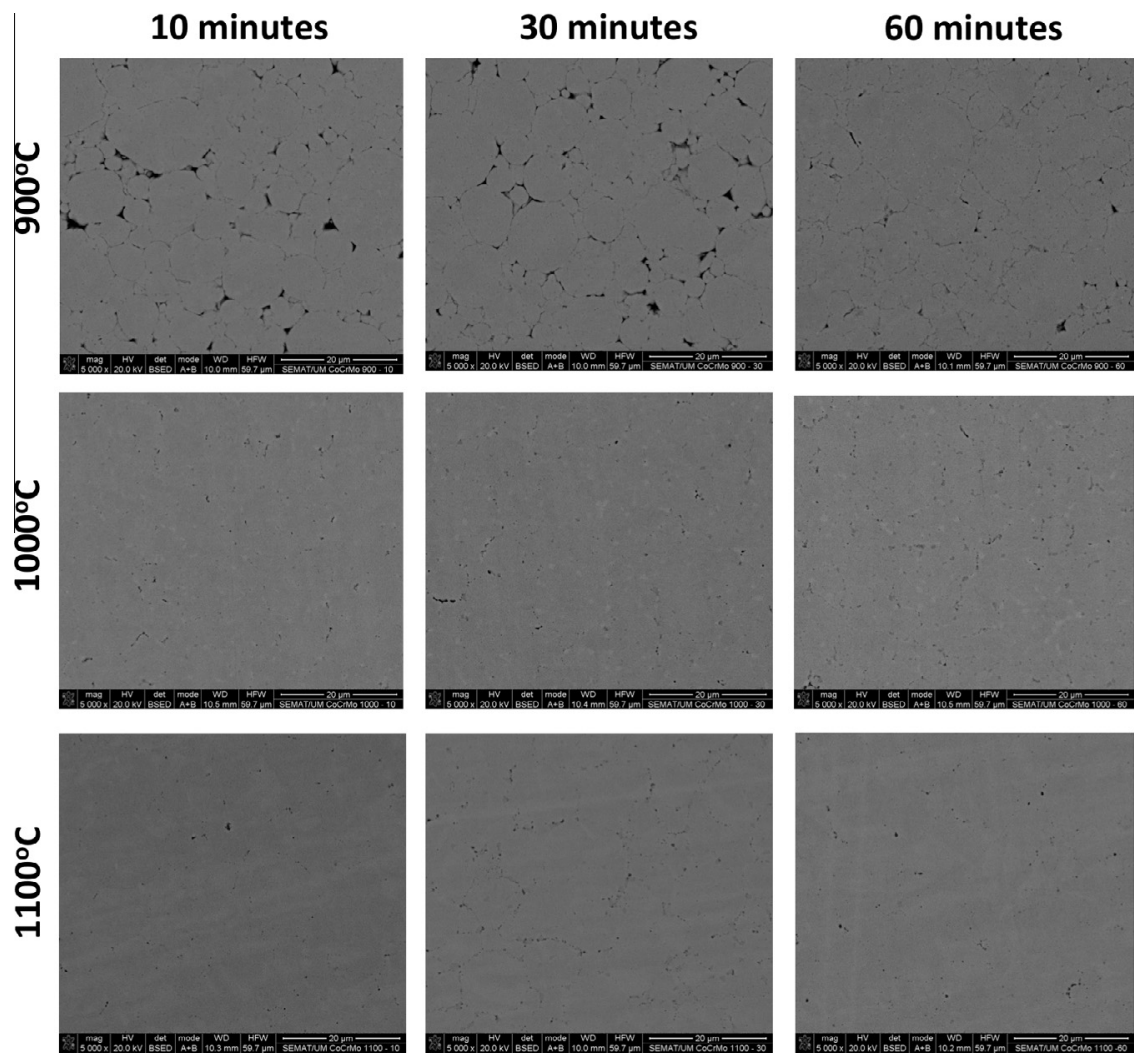

Fig. 6. Micrographs of the CoCrMo compacts hot pressed at different conditions of temperature and time
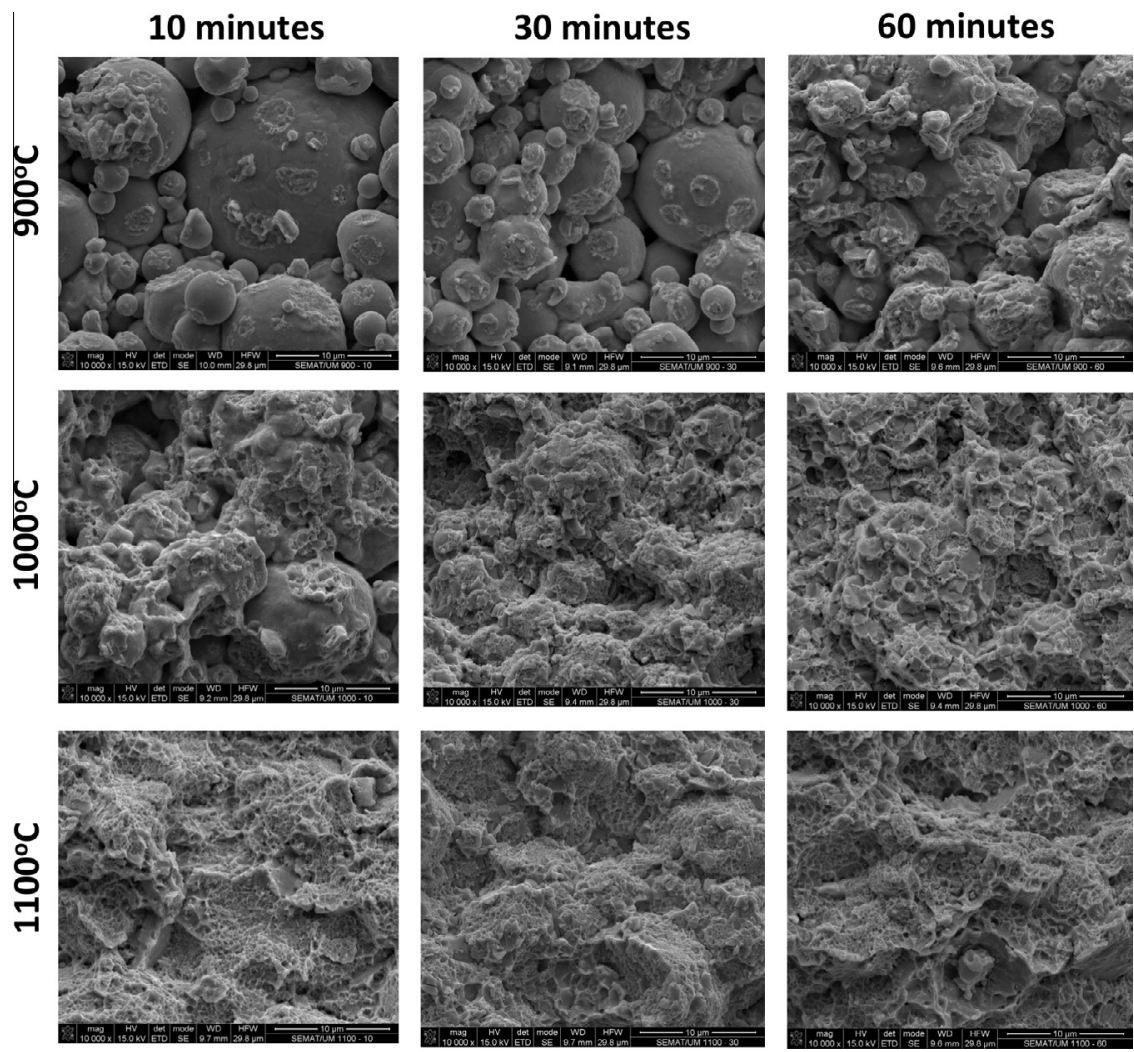

Fig. 7. Fracture surface of the CoCrMo compacts hot pressed at different conditions of temperature and time. 
hardness values. The temperature of $1100^{\circ} \mathrm{C}$ produced softer compacts than the temperature of $1000^{\circ} \mathrm{C}$, for all the hot pressing times tested (Fig. 4). The synergetic effects of two factors explain this: the grain growth occurring at a higher temperature and the absence of $\sigma$-sigma precipitates at the grain boundaries. Sato et al. [26] showed that CoCrMo compacts hot pressed at $1100^{\circ} \mathrm{C}$ did not show precipitates from $\sigma$-sigma phase, conversely to those hot pressed at lower temperatures. The absence of $\sigma$-sigma phase favors the grain growth, which impacts the strength, ductility and hardness of the compacts. Hardness is an important characteristic in a way that hard alloys, combined with high elastic modulus, allow the manufacture of longer prostheses [10]. The higher hardness, thought, may impact the ability to finish/polish the alloy clinically.

A good correlation between the Young's modulus values and the level of porosity of the compacts could be observed, with higher porosity being related to lower stiffness of the compacts. Hence, compacts hot pressed at $900{ }^{\circ} \mathrm{C}$ revealed the lowest stiffness while those hot pressed at $1000{ }^{\circ} \mathrm{C}$ and $1100{ }^{\circ} \mathrm{C}$ for hot pressing times of 30 and 60 min showed maximum stiffness (Fig. 1). Sato et al. [27] reported a significant reduction in porosity with increasing hot pressing temperatures, despite the discrepant values relative to the present study.

The transverse rupture strength (TRS) measured for the compacts hot pressed at $900{ }^{\circ} \mathrm{C}$ was significantly lower than that exhibited by the remaining compacts. Again, the best results obtained for this temperature was observed when the $60 \mathrm{~min}$ hot pressing stage was used. The differences observed for the TRS of compacts hot pressed at $1000^{\circ} \mathrm{C}$ and $1100{ }^{\circ} \mathrm{C}$ were very small, regardless of the hot pressing time used, with the $1000{ }^{\circ} \mathrm{C}$ compacts exhibiting slightly higher values for the hot pressing time of 30 and $60 \mathrm{~min}$. On the other hand, significant differences were observed in the ductility of the compacts, measured by the extension to rupture in the TRS test. The $900{ }^{\circ} \mathrm{C}$ compacts exhibited a fragile behavior while the $1100^{\circ} \mathrm{C}$ compacts exhibited the highest plastic elongation (Fig. 5). These results are in accordance with Sato et al. [26] findings, which reported the highest strength values for the compacts hot pressed at $1000{ }^{\circ} \mathrm{C}$ (explained by the smallest grain size) and the highest plastic elongation for the $1100{ }^{\circ} \mathrm{C}$ compacts (explained by the dissolution of the $\sigma$-sigma phase).

The analysis of the fracture surfaces of the compacts is a useful tool to relate the sintering stage resultant from each hot pressing condition to the mechanical properties obtained. Hence, the weak bonds between powders displayed mainly by the $900{ }^{\circ} \mathrm{C}$ compacts, resulted in low Young's modulus, low hardness, low strength and fragile behavior. On the other side, the effective bonds between the metallic particles, proved by the extensive tearing of the particles at the fracture surface, are related to the higher YM, higher hardness, higher strength and ductile behavior displayed by the compacts hot pressed at higher temperatures.

Some correlations between the properties of the specimens and their processing parameters were evaluated as shown in Figs. 8, 9 and 10.

Correlation between hardness and strength is shown in Fig. 8. As expected more hard materials have also higher strength values. It is also seen that processing time has a major effect only at $900{ }^{\circ} \mathrm{C}$ (blue points - size reflects time), where longer time leads to better results. For 1000 and $1100{ }^{\circ} \mathrm{C}$, this effect however is rather minor.

Links between TRS and elongation at rupture are shown in Fig. 9. For solid materials, normally higher strength means less ductility, but when materials are partially porous (or not well sintered), the link is more complex. Here one can see that the solid materials "rule" is valid for high-temperature processed specimens (1000 and $1100^{\circ} \mathrm{C}$ ), where indeed higher strength is associated with lower elongation. Processing time in this case has no clear

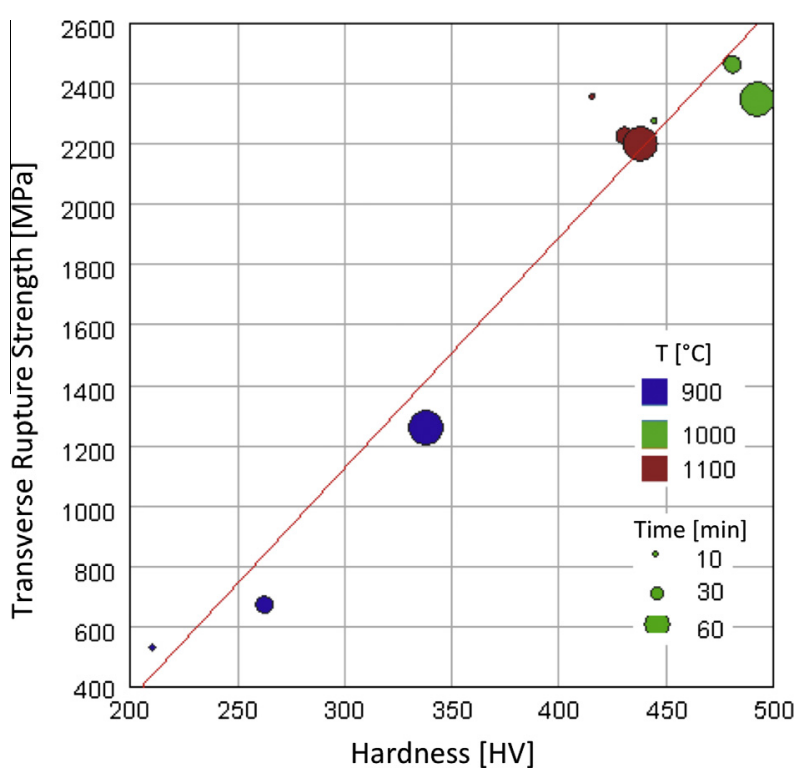

Fig. 8. Correlation between hardness (HV) and strength (TRS).

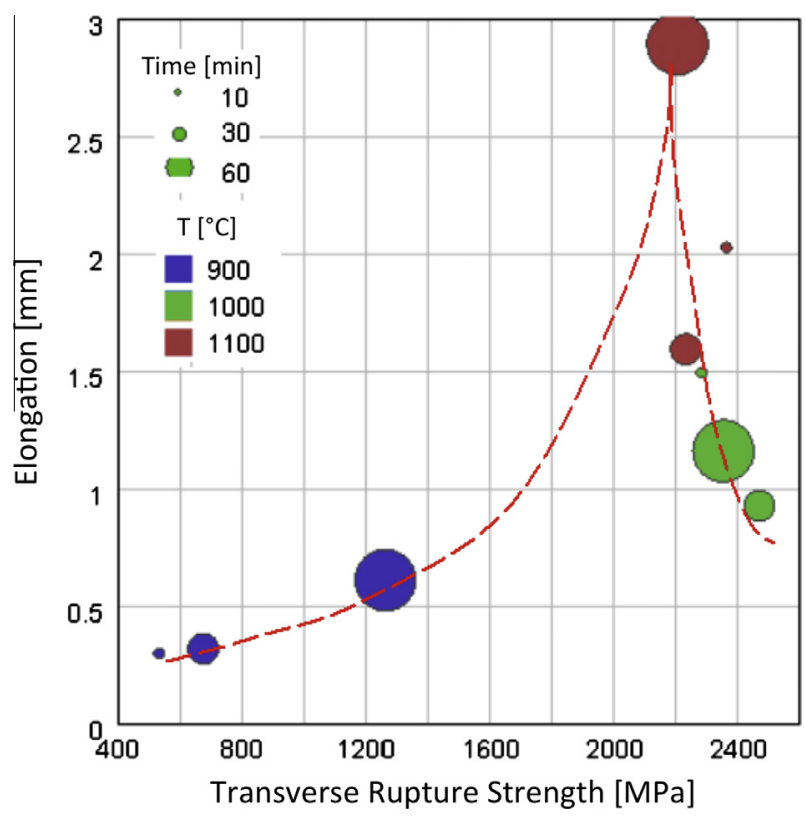

Fig. 9. Correlation between strength (TRS) and elongation at rupture.

effect, as higher strength might be found at intermediate or lower time, on the contrary to $900^{\circ} \mathrm{C}$.

Effect of porosity on Young's modulus is shown in Fig. 10. Dashed lines indicate trends, connecting the experimental points with the same processing time $(10,30,60 \mathrm{~min})$. One can observe that temperature increase has the most of effect for short time (10 $\mathrm{min}$ ), but for 30 and $60 \mathrm{~min}$ the increase of the modulus is only seen vs. values obtained at $900{ }^{\circ} \mathrm{C}$.

The conclusions, which could be made of these plots, can be used for recommended processing selection. It is clear that $900{ }^{\circ} \mathrm{C}$ is too low temperature to cope with higher demand for properties, as even at longer processing time (lower porosity), the modulus, elongation and hardness are still of an average level. The value of $1000{ }^{\circ} \mathrm{C}$ and $30 \mathrm{~min}$ seem to be a good compromise to achieve reasonably low porosity, high modulus and strength with $\sim 1 \%$ elongation. If higher ductility is required, temperature of $1100{ }^{\circ} \mathrm{C}$ and 60 min time possibly will be a better option. 


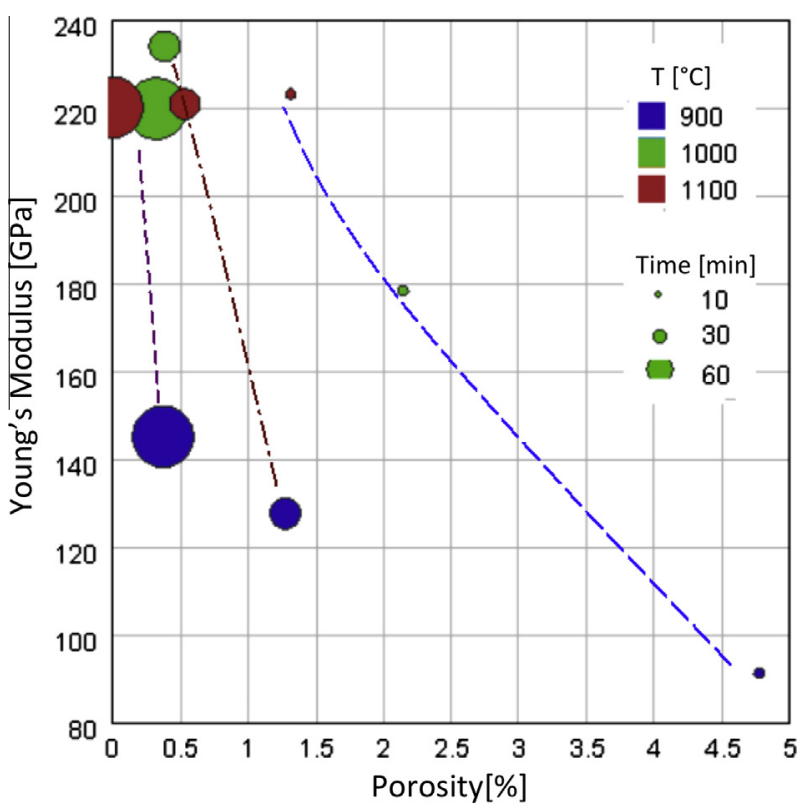

Fig. 10. Plot of the effect of porosity on Young's modulus (YM).

\section{Conclusions}

From this study, the following conclusions can be drawn:

1. The properties of the CoCrMo compacts showed to be significantly affected by the processing conditions, namely the temperature and time;

2. The hot pressing temperature of $900{ }^{\circ} \mathrm{C}$ showed to impart to compacts high porosity, low mechanical strength, low hardness and low Young's modulus, particularly using short sintering times;

3. The hot pressing temperatures of $1000^{\circ} \mathrm{C}$ and $1100{ }^{\circ} \mathrm{C}$ showed to result in compacts with similar mechanical strength, porosity and Young's moduli. However, higher hardness values were registered for $1000{ }^{\circ} \mathrm{C}$ compacts when compared to those hot pressed at $1100^{\circ} \mathrm{C}$.

4. The $900{ }^{\circ} \mathrm{C}$ compacts exhibited brittle behavior while $1000{ }^{\circ} \mathrm{C}$ and $1100^{\circ} \mathrm{C}$ compacts exhibited increasing ductility with increasing hot pressing temperature;

5. This study has shown that hot pressing is a feasible technique for the production of CoCrMo compacts for biomedical applications with adequate mechanical properties. The mechanical strength, porosity, Young's moduli and hardness can be adjusted by tuning the processing conditions.

\section{Acknowledgements}

The authors acknowledge the Portuguese Foundation for Science and Technology (FCT - SFRH/BPD/87435/2012; EXCL/EMS-TEC/0460/2012; PEst-OE/EEA/UI04436/2015) for the financial support.

\section{References}

[1] M.M. Dewidar, H. Yoon, J.K. Lim, Mechanical properties of metals for biomedical applications using powder metallurgy process: a review, Met. Mater. Int. 12 (3) (2006) 193-206.
[2] R.W. Hsu, C. Yang, C. Huang, Y. Chen, Electrochemical corrosion studies on CoCr-Mo implant alloys, Mat. Chem. Phys. 93 (2005) 531-538.

[3] M. Metikoš-Huković, R. Babić, Passivation and corrosion behaviors of cobalt and cobalt chromium-molibdenium, Cor. Sci. 49 (2007) 3570-3579.

[4] M.A. Ameer, E. Khamis, M. Al-Motlaq, Electrochemical behavior of recasting $\mathrm{Ni}-\mathrm{Cr}$ and $\mathrm{Co}-\mathrm{Cr}$ non-precious dental alloys, Corr. Sci. 46 (2004) 2825-2836.

[5] Z. Doni, A.C. Alves, F. Toptan, L.A. Rocha, M. Buciumeanu, L. Palaghian, F.S. Silva Tribocorrosion behaviour of hot pressed CoCrMo-HAP biocomposites, Tribology Int. (2015), http://dx.doi.org/10.1016/j.triboint.2015.04.009.

[6] Y. Chen, Y. Li, S. Kurosu, K. Yamanaka, N. Tang, A. Chiba, Effects of microstructures on the sliding behavior of hot-pressed CoCrMo alloys, Wear $319(1-2)$ (2014) 200-210.

[7] Sh. Zangeneh, H.R. Lashgari, A. Roshani, Microstructure and tribological characteristics of aged Co-28Cr-5Mo-0.3C alloy, Mater. Des. 37 (2012) 292303.

[8] T. Matković, P. Matković, J. Malina, Effects of Ni and Mo on the microstructure and some other properties of Co-Cr dental alloys, J. All. Comp. 366 (1-2) (2004) 293-297.

[9] S. Mineta, S. Namba, T. Yoneda, K. Ueda, T. Narushima, Carbide formation and dissolution in biomedical Co-Cr-Mo alloys with different carbon contents during solution treatment, Met. Trans. 41A (2010) 2129-2138.

[10] R.G. Craig, J.M. Powers, Restorative Dental Materials, 11th ed., Mosby, 2002. pp. 480-492.

[11] K. Yamanaka, K. Mori, K. Kuramoto, A. Chiba, Development of new Co-Cr-Wbased biomedical alloys: effects of microalloying and thermomechanical processing on microstructures and mechanical properties, Mater. Des. 55 (2014) 987-998.

[12] K. Yamanaka, M. Mori, A. Chiba, Effects of nitrogen on microstructural evolution of biomedical $\mathrm{Co}-\mathrm{Cr}-\mathrm{W}$ alloys during hot deformation and subsequent cooling, Mater. Des. 57 (2014) 421-425.

[13] M. Dourandish, D. Godlinski, A. Simchi, V. Firouzdor, Sintering of biocompatible $\mathrm{P} / \mathrm{M}$ Co-Cr-Mo alloy (F-75) for fabrication of porosity-graded composite structures, Mater. Sci. Eng. A 472 (2008) 338-346.

[14] B. Henriques, D. Soares, F. Silva, Shear bond strength of a hot pressed Au-Pd-Pt alloy-porcelain dental composite, J. Mech. Behav. Biomed. Mater. 4 (8) (2011) 718-1726.

[15] B. Henriques, D. Soares, F. Silva, Optimization of bond strength between gold alloy and porcelain through a composite interlayer obtained by powder metallurgy, Mater. Sci. Eng. A 528 (2011) 1415-1420.

[16] B. Henriques, D. Soares, F. Silva, Microstructure, hardness, corrosion resistance and porcelain shear bond strength comparison between cast and hot pressed CoCrMo alloy for metal-ceramic dental restorations, J. Mech. Behav. Biomed. Mater. 12 (2012) 83-92.

[17] B. Henriques, S. Felix, D. Soares, F. Silva, Shear bond strength comparison between conventional porcelain fused to metal and new functionally graded dental restorations after thermal-mechanical cycling, J. Mech. Behav. Biomed. Mater. 13 (2012) 194-205.

[18] B. Henriques, D. Soares, F. Silva, Hot pressing effect on the bond strength of a CoCrMoSi alloy to a dental porcelain, Mater. Sci. Eng. C 33 (1) (2013) 557-563.

[19] B. Henriques, M. Gasik, J. Souza, D. Soares, R.M. Nascimento, F.S. Silva Mechanical and thermal properties of hot pressed CoCrMo-porcelain composites developed for prosthetic dentistry, J. Mech. Behav. Biomed. Mater. 30 (2014) 103-110.

[20] Z. Oksiuta, J.R. Dabrowskia, A. Olszynab, Co-Cr-Mo-based composite reinforced with bioactive glass, J. Mater. Proc. Technol. 209 (2009) 978-985.

[21] M. Grądzka-Dahlke, J.R. Dąbrowski, B. Dąbrowski, Modification of mechanica properties of sintered implant materials on the base of Co-Cr-Mo alloy, J. Mater. Proc. Technol. 204 (1-3) (2008) 199-205.

[22] W.C. Rodrigues, L.R. Broilo, S. Lírio, G. Knörnschild, F.R.M. Espinoza, Powder metallurgical processing of $\mathrm{Co}-28 \% \mathrm{Cr}-6 \% \mathrm{Mo}$ for dental implants: physical, mechanical and electrochemical properties, Pow. Technol. 206 (3) (2011) 233 238.

[23] E. Krasicka-Cydzik, Z. Oksiuta, J.R. Dabrowski, Corrosion testing of sintered samples made of the Co-Cr-Mo alloy for surgical applications, J. Mater. Sci.: Mater. Med. 16 (2005) 197-202.

[24] K. Wu, G. Liu, B. Hu, F. Li, Y. Zhang, Y. Tao, J. Liu, Hot compressive deformation behavior of a new hot isostatically pressed $\mathrm{Ni}-\mathrm{Cr}-\mathrm{Co}$ based powder metallurgy superalloy, Mater. Des. 32 (4) (2011) 1872-1879.

[25] Z. Doni, A.C. Alves, F. Toptan, F.R. Gomes, A. Ramalho, M. Buciumeanu, L Palaghian, F.S. Silva, Dry sliding and tribocorrosion behaviour of hot pressed CoCrMo biomedical alloy as compared with the cast CoCrMo and Ti6Al4V alloys, Mater. Des. 52 (2013) 47-57.

[26] Y. Sato, N. Nomura, S. Fujinuma, A. Chiba, Microstructure and mechanica properties of hot-pressed Co-Cr-Mo alloy compacts, Adv. Mat. Res. 26-28 (2007) 769-772.

[27] Y. Sato, N. Nomura, S. Fujinuma, A. Chiba, Microstructure and tensile properties of hot-pressed Co-Cr-Mo alloy compacts for biomedical applications, J. Japan Inst. Metals (2008) 532-537.

[28] N. Naoyuki, A. Mariko, K. Atsushi, F. Shigeo, C. Akihiko, M. Naoya, H. Shuji, Fabrication and mechanical properties of porous $\mathrm{Co}-\mathrm{Cr}-\mathrm{Mo}$ alloy compacts without Ni addition, Mater. Trans. 47 (2) (2006) 283-286. 